\title{
LA DISPUTA ENTRE FOUCAULT Y DERRIDA POR LOS RESTOS DE DESCARTES \\ (1' PARTE)
}

Cristina de Peretti

(UNED)

El hilo que, siempre tortuosa y a menudo subterráneamente, guiará este texto tiene mucho que ver con las complicadas relaciones, cómplices a veces y otras veces antagónicas, que, dentro del lenguaje, se tejen y destejen entre la escritura fillosótíca y la literatura. Complicación que se agrava aún más cuando de lo que se trata - y ésta es la tremenda apuesta en la que se ven implicados los tres pensadores de los que aquí me voy a ocupar: Descartes, Foucault y Derrida- es de saber cuál es el lugar — si lo hay - desde el cual ese resto impensado y, al parecer, tradicionalmente impensable del pensamiento, ese exceso y desmesura de la razón, en una palabra, la locura, lo Otro del pensamiento, puede decir su nombre, hablar por si misma, en su propio nombre y en nombre propio.

Para ello, habrá que empezar, quizás, por recuperar asimismo esos otros restos. esta vez, materiales, corpóreos, que son los textos escritos de Descartes: textos que se ponen, pues, en marcha como otras tantas "cabezas de lectura" en las cuales se injertan, engendrándose, nutriéndose y diseminándose mutuamente, esos textos en los que Foucault y Derriưa discuten sobre la locura y dialogan con ella.

¿Cómo mantener y articular un discurso de la locura resistiendo a todos los discursos sobre la locura que reducen a ésta al silencio? ¿Es posible semejante discurso? Y, si asi fuera ¿desde qué espacio se le restituye a la locura el habla, el derecho al habla? ¿Es capaz el discurso filosófico de decir el afuera del lenguaje dentro del lenguaje? ¿Es capaz de hablar dentro del afuera de la filosofia? $O$, por el contrario, ¿es la literatura el único espacio capaz de acoger, de dar cabida a la locura, la gran excluida, según Foucault, de la filosofia, del pensamiento?

Antes de tratar de abordar estas complejas cuestiones, comenzaré, más sencillaniente, por recordar ese recurso supuestamente literario tan utilizado, sin embargo, en el texto escrito de la filosofia. Me estoy refiriendo a la metáfora que, por cierto, es ante todo el nombre de un concepto filosófico.

En efecto, el carácter claramente autobiográfico del Discurso del método de Descartes, obra destinada a un público general y no a especialistas, convierte dicho texto en una doble metáfora del camino, porque si, por una parte, el verbo discurrir viene del latín discurrere que significa "correr aqui y allá", por otra parte, el término "método" mantiene aquí su sentido etimológico más genuino: el de un camino por el que se discurre con la vista puesta en una meta. La metáfora del camino, sin duda alguna, resulta trivial y muy manida. No obstante, en el Discurso del método, dicha metáfora toma unos derroteros muy personales: se trata de descubrir el camino que cada uno ha de recorrer construyéndolo, si es necesario, a cada paso. Esto es, se trata ante todo de "conducir" bien la razón, de avanzar lentamente, siguiendo siempre el "camino recto", sin perderse. Después de haber viajado mucho, tras haber "recorrido todos los libros", el filósofo va mostrando cuál es el camino que él ha tomado, avanzando a tientas, casi a ciegas, tanteando el terreno, "como un hombre que camina solo y en medio de las tinieblas".

El recurso que de la netátora hace el Discurso no termina aqui: la omnipresente metáfora del camino cede en ocasiones el paso a esa otra metálora mucho más estática: la de la arqui- 
tectura. Construcciones, ciudades y edificios en ruinas o mal construidos, mal asentados sobre un suelo poco firme: más vale acabar con ellos de una vez por todas, borrarlos del mapa para siempre. Un final muy similar es el que sin duda espera, en la senda emprendida por Descartes de búsqueda de la verdad a través de la duda metódica, a todos esos conocimientos que funcionan como verdaderos $y$ ciertos pero que no son sino viejas opiniones y creencias heredadas acriticamente por el hombre. Ahora bien, a la metáfora de estas construcciones mal fundamentadas, poco firmes o ruinosas, se suma asimismo otra metáfora que, siendo arquitectónica, es también algo más: la metáfora del habitáculo cuya imagen más conocida es esa habitación, esta vez no metafórica, que calienta una estufa y en la que Descartes se encierra solo, durante todo el día, para pensar y escribir. La imagen, pues, que Descartes ofrece de si mismo, en 1637, no deja de ser sosegada y tranquilizadora.

Muy semejante resulta, al menos en apariencia, el cuadro, tal vez incluso aủn más hogareño, que describe Descartes a! principio de sus Meditaciones metafisicas: está sentado, vestido con una bata, junto a una estufa, $y$ con un papel en la mano (escena a la que alude muy explicitamente el título del texto de Foucault: "Mon corps, ce papier, ce feu"). Pero es, precisamente, en medio de esta serena y doméstica escena de un Descartes que lee y/o escribe, sujeto pensante al calor de un buen fuego, en donde surge, de repente, la inhóspita, inquietante y aterradora amenaza de la locura.

La preocupación que guia a Descartes en las Meditaciones sigue siendo la misma que la del Discurso: es preciso no admitir nada en lo que pueda haber el más minimo motivo de duda. Y ello, precisamente, a fin de que el pensamiento se asiente sobre una base firme, sobre un entramado sólido y consistente de auténticas certezas, las cuales, para convertirse en tales, precisan una rigurosa fundamentación.

Ahora bien, dicho esfuerzo no entraña en las Meditaciones los mismos problemas que en el Discurso. En este último, el proceso de duda no alcanza la universalidad y radicalidad que logra tanto en los Principia como en las Meditaciones, ambas obras destinadas a un público cspecializado. Por otra parte, en las Meditaciones, ya no se va a requerir, como si ocurre en cambio en el Discurso, una moral provisional. Tampoco se planteara ya aqui la cuestión de la autoridad y de la legitimidad. El sujeto que habla en las Medisaciones autoriza y afirma su propia legitimidad como fundador de una filosofia que busca la certeza absoluta. Y sin necesidad de revisar uno por uno los motivos de duda que afectan a las verdades concretas, a Descartes le bastará, por consiguiente, para llevar a buen tèrmino su proyecto, con recorrer los motivos de duda que hacen peligrar los principios sobre los que se consolida toda certeza.

La Primera Meditación se abre, pues, con la consideración de que toda verdad recibida por medio de los sentidos ha de ser puesta en duda, pues éstos, en numerosas ocasiones, han demostrado ser enganosos. Y aunque parece haber cosas sensibles de las que "razonablemente no se puede dudar" (por ejemplo, en lo que respecta a determinada relación externa, sensorial y corporal con el mundo), no resulta ilógico pensar que, si los sentidos nos han enganado alguna vez, nos pueden volver a engañar siempre. A fin de generalizar todavia más la duda a todo conocimiento sensible, a todas las ideas de origen sensible, Descartes recurre, en un segundo momento, al motivo del sueño, al engaño que a menudo entraña el no poder distinguir claramente entre la vigilia y el sueño, puesto que en los sueños nos parece ver y experimentar las mismas cosas que creemos conocer en estado de vigilia.

"Pero ¿y qué? son unos locos y yo no sería menos extravagante si me rigiera por sus ejemplos": ésta es la frase de las Meditaciones metafisicas de Descartes que sirve de punto de arran- 
que, allá por los años 60 , para el ya viejo y no por ello menos apasionante debate entre Foucault y Derrida del que ya voy a ocuparme de aqui en adelante.!

Son abundantes, a menudo intrincados e incluso, en ocasiones, soterrados los textos que, por parte de ambos, mantienen viva dicha polémica a lo largo ya de más de treinta años. Y no menos numerosos son, por cierto, los estudiosos de Foucault y de Derrida que han dedicado muchas horas, muchos esfuerzos y muchas páginas a debatir y arbitrar dicha controversia.

No es mi intención sumarme, aquí, a esta polémica ni siquiera para esbozar a grandes trazos el conjunto de su trayectoria. Además de respetar las razones personales y de suscribir los argumentos filosóficos (entre otros, sobre todo, el de que no puede haber testimonio de la locu$\mathrm{ra}$ ya que todo testimonio no pretende sino dar razón, objetivar, fiscalizar) que, en "Être juste avec Freud...", su último texto sobre Foucault ${ }^{2}$ y ya después de la muerte de éste, expone Derrida para no reanudar el debate, entiendo que pretender resolver quién tiene razón en una. discusión que, precisamente, gira en torno a la locura, esto es, a eso que casi siempre se ha dado en denominar la sin-razón no puede dejar de resultar sospechoso, sobre todo - pero tal vez no sólo- en un caso como éste, en el que el hecho mismo de tener razón, es decir, asimismo de tener la razón, de tenerla y de poseerla como algo que nos hace dueños de ella, pero también,

1 En 1961, Foucault publica su Folie et déraison. Histoire de la folie à l'áge classique (Paris, Plon). El 4 de Marzo de 1963, en el Collège Philosophique, Derrida inicia la controversia con Foucault pronunciando una conferencia sobre diclo libro: "Cogito et histoire de la folie", cuyo texto publica primero en la Revue de Métaphysique et de Morale, 3/4, 1964 y, más adelante, en L'écriture et la différence, Paris, Seuil, 1967.

Foucault no contesta a la critica de Derrida pero, bajo cuerda. Ia polémica va fraguándose lentamente con textas como, por parte de Foucault, "La folie, l'absence d'oeuvre" (La Table ronde, 196, Mayo de 1964 que. posteriormente, se publicara como $1^{\circ}$ apéndice de la 2 edición de Folie et déraisun, libro que esta vez se publicará con el titulo de Histoire de la folit à l'âge classique. Paris, Gallimârd, 1972) y "Qu'est-ce qu'un anteur?" (Bulletin de la Société Fronçaise de Philosophie, 63, 1969); por pante de Derrida, "La parole soufllice" (Tel Quel, 20, Inviemo 1965, posteriormente publicado en L'ecriture et la différence, ed.cit.) y "Signature, évènement, contexte" (Conferencia presentada en Montreal en 1971, y posteriormente publicada en Marges de la plilosophie, Paris, Minuit, 1972).

En el ano 1972 aparece, pues, la Histoire de la tolie a l’âge classique (Paris, Gallimard): en ella, Foucault suprime el prologo de la edición anterior, publica otro más breve y añade asimismo dos apéndices: el primero, ya mencionado; y el segundo, "Mon corps, ce papier, ce feu" que constituye, por fin, desputs de nueve años de aparente silencio, una respuesta explícita si bien no exloustiv'a al texto de Derrida de 1963. Una primera versión de esta respuesta de Foucault: "Michel Foucault Derrida e no kaino" aparece en la revista japonesa Paideia, $17^{\circ} 11,1972$. Actualmente, se encuentra asimismo publicada, bajo el titulo, "Riponse a Derrida" en el torno $2^{\circ}$ (1970-1975) de los Dits et écrits (1954-1988) (Edición establecida bajo la dirección de D. Defent y F. Ewald con la colaboración de J. Lagnange. Paris, Gallimard, 1994).

Esta yez es Derrida quien va a guardar silencio. Por mzones ajenas a dicha controversia (encarcelauniento de Derrida en Praga e incondicional apoyo de Foucault para su puesta en libertad). a principios de 1982 y hasta la muerte de Foucault en 198.4, este ćltimo y Derrida reanudan una buena amistad interrumpida durante tantos ailos.

Posteriormente, y' tras la muerte de Foucault, Derrida volverá a hablar y' a escribir sobre aquél. Adeniss de la conferencia inéstita titulada "Au-delà du principe de pouroir" que Derrida pronuncia en abril de 1986, en la Universidad de Nueva York, en el transcurso de un homenaje a Foucault organizado por Tliomas Bishop. En modo alguno tratará Derrida de reanudar la controversia con Foucault. Asi lo dice explicitamente en esa otra conlerencia que da en noviembre de 1991, en el Gran Anliteatro de Sainte-Anne, en donde la Sociedad Intemacional de Ilistoria de la Psiquiatrla y del Psicoanálisis contnemora. precisamente, el trigésimo aniversario de la publicación de la llistoire de la folie a l'äge classique. El texto de esta conferencia, bajo el titulo, "Être juste avee Freud. L'histoire de la folie à l'ảge de la psy'clianaly'se" se publica en una obra colectiva da lomenaje a Foucault: Penser la folie. Essais stur Micled Fotscault (Paris. Galilie, 1992) y, posteriormente, junto con otros textos de Derrida sobre psicoanólisis, en su libro titulado: Résistances de la psyclanalyse (1'aris, Galitée, 1995).

2 DERRIDA, J.: "Etre juste avec Freud. L'histoire de la folie a l'âge de la psyclanaly'se" en $A$ A.VV.: Penser la folie. Ed. cit., p. 142-143. 
por consiguiente, de nosotros mismos, supone que dicha posesión constituye, al menos en apariencia, la imposibilidad misma de la enajenación, de la locura, poniendo, asi, casi necesariamente en entredicho la autoridad y legitimidad del que pudiera tener "la" razón a la hora de restituir el discurso de la locura (entendiendo éste como un doble genitivo: objetivo y', sobre todo quizás, subjetivo). Éste que, a simple vista, puede parecer un mero juego de palabras, no es, a mi entender, una cuestión baladi, pues, más allá de todas las objeciones y respuestas que tejen la controversia Foucault-Derrida, lo que dicho debate pone en juego es -como ya señalé al comienzo- el problema de la posibilidad misma de dicho discurso y del lugar que éste ocuparía dentro del pensamiento.

Aunque, desde el siglo pasado hasta nuestros dias, debido sin duda a una nueva experiencia del lenguaje, la filosofia se hace, cada vez más, cargo de la locura como una experiencia singular del pensamiento, terreno éste cn el que, en tiempos pasados, la locura ocupaba un lugar muy remoto, un espacio muy exiguo, si no inexistente, puesto que se la consideraba sobre todo como algo perteneciente al ámbito de la literatura, Foucault y Derrida parecen estar de acuerdo en que todavía hoy, el único lugar de encuentro posible entre la locura y el pensamiento, entre la locura y la filosofia, si se prefiere, sigue siendo la ficción, lo que Derrida denomina "el lenguaje de la fícción o [...] la ficción del lenguaje". 3

Dicho esto, como es de suponer, la ficción, como tal lugar de encuentro, no desempena, para Foucault y Derrida, el mismo papel con respecto a la filosolia. Ni desempeña tampocio el mismo papel en Descartes, si nos atenemos a las lecturas que ambos filósofos lacen del texto escrito cartesiano.

Según Foucault, y dado que la filosofia, la psicología y la psiquiatria parten de un desconocimiento radical del lenguaje de la locura, toda la historia de Occidente seria la historia de una conqquista progresiva de la razón, de un predominio de la misma $\mathrm{y}$, por consiguiente, también la historia de una represión de la locura.

Tras describir la experiencia cósmica, dramática, de la locura en el Renacimiento a lo largo del capitulo 1 de su Historia de la locura en la época clasica, Foucault apunta, en el capitulo 2, un giro decisivo en esta historia: giro que viene dado por el Cogito cartesiano y, más concretamente, por ese momento de la $1^{3}$ de las Meditaciones, momento en el que Descartes, en su camino de búsqueda de la verdad a través de la duda metódica. se encuentra con la locura y escribe esta frase: "Pero iy qué? son unos locos y yo no sería menos extravagante si me rigiera por sus ejemplos". Para Foucault, dicha sentencia arroja a la locura fuera de los limites del pensamiento y la reduce al silencio.

Sólo a partir de Le Neveu de Rameau de Diderot, irrumpa la locura en el ámbito del lenguaje literario ganando terreno en la época del romanticismo. A partir de principios del siglo XIX, la literatura reconocerá la locura como tema suyo pero la filosolia se resistirá y seguirá cxcluyendo dicho reconocimiento. Por eso, para Foucault, las ficciones de la locura que atestan los textos dificilmente clasificables de esos grandes locos geniales que, entre otros, fueron Sade, Hölderlin, Nictzsche, Nerval, Roussel, Artaud, etc..., y que ponen asi en entredicho la escisión misma entre el pensamiento y la locura, consiguen básicamente desorientar, desamparar al pensamiento, en una palabra, dar testimonio en contra de la lïlosofia, en contra de ese pensamiento filosólico que, por su parte, sólo piensa, mediante el lenguaje de la razón, en excluir la locura y' reducirla al silencio. La locura sólo puede ser, para Foucault, ausencia de

\footnotetext{
3 DERRIDA, J.: "Cogito et histoire de la folie" en Leicrisure et la diffirence. Ed. cit., p. 84.
} 
obra, pérdida de sentido, inacabamiento tanto más activo y vertiginoso cuanto que la locura es ante todo la imposibilidad de dominar su propia ficción.

Para Derrida, en cambio, la fícción de la locura es la que termina, en cierto modo, por orientar al pensamiento puesto que la razón de la filosofia no es sino la economia de su propia locura. La relación entre el lenguaje y la locura es de exclusión esencial. Esto es, dicha relación de exclusión no es algo que se pueda determinar históricamente, como en algún momento pretende hacerlo Foucault: no es un acontecimiento histórico, sino que es el hecho general y constitutivo de todo discurso, la condición misma del lenguaje, cuya econornia, cuya estrategia de autoprotección consiste, precisamente, en que la locura no pueda ser dicha en el lenguaje, en el logos.

Ahora bien, para Derrida, tanto la razón pura como la pura locura son imposibles. No hay razón que no esté contaminada por la locura ni locura que no lo esté por la razón. Por eso, para Derrida, el propio proyecto del cogito cartesiano es ya un loco propósito y, como tal, este no tiene más remedio que salvaguardar el decir de su discurso contra esa locura que respalda su insensato y ambicioso designio a la vez que lo amenaza a cada paso. De ali que ni el proceso de duda cartesiano - que, ya muy concretamente en la $l^{3}$ Meditación, no discute sobre la objetividad de la verdad sino que va dirigido contra la certeza, esto es, contra un estado de supuesta plenitud subjetiva- ni el acto del cogito, primera certeza absoluta que surgirá de la duda, sean ajenos a que esa locura, que al parecer es lo más extrano, lo más excesivo, lo más desmedido, irrumpa inesperadamente en medio del pensamiento, en medio de aquella escena en la que Descartes, vestido con una bata, piensa y escribe tranquilamente junto al fuego: cuadro tanto más lrogareno, intimo y sosegado que no otra es la imagen que el pensamiento trata desesperadamente de forjarse y de dar de si mismo.

Ni la filosofia escapa del todo a la locura, ni esta, por su parte, desaparece tampoco totalmente del pensamiento. Ese resto del pensamiento, que es la locura, resiste al pensamiento y a su exclusión por parte del mismo, a la vez que lo excede. Y lo excede no sólo porque, en cierto modo, lo supera, lo rebasa, sino también porque se sale de la regla, de la normalidad $y$, de este modo, lo irrita, lo perturba, en una palabra, lo contamina con esa "otredad" que al pensamiento se le hace irrecibible, esto es, insoportable de acoger dentro de sí.

"Yo, que pienso, no puedo estar loco", asegura Foucault —n la Historia de la locurarefiriéndose a la exclusión a la que, según él, el pensamiento -y concretamente aqui el pensamiento cartesiano- condena a la locura. ${ }^{4}$ Para él, no sólo "Descartes no evita el peligro de la locura como evade la eventualidad del sueño o del error" (puesto que, como ya señalé anteriormente, estos últimos afectan al objeto del pensamiento mientras que el primero atante al sujeto pensante), sino que, además, en su posterior réplica a Derrida, y a propósito, precisamente, de la hipótesis cartesiana del genio maligno, Foucault declarará que dicha ficción es "otra cosa que la locura".5 El sujeto pensante, dirá Foucault, sólo se interna en la ficción para salir de ella puesto que, como tal sujeto pensante, termina siempre por dominarla y recobrar el rumbo. El loco, en cambio, es aquél que ya no encuentra su camino dentro la ficción y sucumbe a ella y en ella.

Derrida, por el contrario, sostiene que es justamente con la hipérbole demónica, hipérbole que es anterior al cogito pero que persiste asimismo, constantemente al acecho, tris esa primera certeza absoluta, con la que Descartes asumirá hasta sus más extremas consecuencias la posibilidad de la locura dentro del pensamiento: "Que yo esté loco o no, Cogitum. sum" lee

4 FOUCAULT, M.: Hisıoire de la folie à / Tìge classigne. Ed. cit., p. 57.

5 FOUCAULT, M.: Op. cit., p. 56. 
Derrida en Descartes. ${ }^{6}$ El genio maligno no puede lograr que yo no piense cuando dudo, ni cuando no sé siquiera si cstoy loco. El cogito, el "yo pienso", es, por lo tanto, una certeza inquebrantable. Pero, además, para pensar hay que ser. El cogito entraña, pues, a su vez, esa otra certeza que es mi existencia: "Cogito, ergo sum" (o "Cogito, sum"). Aunque el genio maligno me engañe totalmente, aunque yo esté loco, el acto del cogito siempre es válido, no ya porque excluye la locura, como señala Foucault, sino, precisamente, porque acoge dentro de si la posibilidad misma de la locura: a saber, la posibilidad de que el pensamiento no sea puro ni dueño de sí mismo, la posibilidad de que yo no tenga razón, de que no tenga "la" razón, de que no sea dueño absoluto ni de ella ni de mi mismo y de que, por consiguiente, pese a una aparente racionalidad, los juicios que emite el sujeto pensante puedan ser irracionales. Lo cual no le impedirá en modo alguno a dicho sujeto seguir pensando y existiendo como tal.

El debate está archivado, aduce Derrida, entre otros argumentos, para no reiniciar la polı́mica con Foucault una vez que éste ya ha muerto. Ahora bien, en ese otro texto suyo titulado Mal d'archive, ${ }^{7}$ Derrida cuestiona precisamente la posibilidad de que un archivo se pueda dar por cerrado alguna vez. Por eso, y a pesar de todo, el archivo no sellado de esta polémica -a la que, finalmente, no puede sin duda laber dejado de sumarse, aún sin quererlo, este texto- queda pues abierto, aqui y ahora, susceptible de otras tantas lecturas y re-escrituras que a su vez lo tornan siempre interminable.

6 DERRIDA, J.: "Cogito et histoire de la folie" en L'écrinure et la difjirence. Ed. cit., p. 86.

7 DERRIDA, J.: Mal d'archire. Paris, Galilée, 1995. 